\title{
Weaving Nanoscale Cloth through Electrostatic Templating
}

Anouck M. Champsaur, ${ }^{\dagger}$ Cécile Mézière, ${ }^{\ddagger}$ Magali Allain, ${ }^{\ddagger}$ Daniel W. Paley, ${ }^{\dagger, \S}$ Michael L. Steigerwald, ${ }^{*}{ }^{\dagger}$ Colin Nuckolls, $*,+$ a

${ }^{\dagger}$ Department of Chemistry, Columbia University, New York, New York 10027, United States

${ }^{\ddagger}$ Laboratoire MOLTECH, CNRS UMR 6200, Université d’Angers, 49045 Angers, France

${ }^{\S}$ Columbia Nano Initiative, Columbia University, New York, New York 10027, United States

Supporting Information

ABSTRACT: Here we disclose a simple route to nanoscopic $2 \mathrm{D}$ woven structures reminiscent of the methods used to produce macroscopic textiles. We find that the same principles used in macroscopic weaving can be applied on the nanoscale to create two-dimensional molecular cloth from polymeric strands, a molecular thread. The molecular thread is composed of $\mathrm{Co}_{6} \mathrm{Se}_{8}\left(\mathrm{PEt}_{3}\right)_{4} \mathrm{~L}_{2}$ superatoms that are bridged with $\mathrm{L}=$ benzene bis-1,4-isonitrile to form polymer strands. As the superatoms that make up the polymer chain are electrochemically oxidized, they are electrostatically templated by a nanoscale anion, the tetragonal Lindqvist polyoxometalate $\mathrm{Mo}_{6} \mathrm{O}_{19}{ }^{2-}$. The tetragonal symmetry of the dianionic template creates a nanoscale version of the box weave. The crossing points in the weave feature $\pi$-stacking of the bridging linker. By examining the steps in the weaving process with single crystal X-ray diffraction, we find that the degree of polymerization at the crossing points is crucial in the cloth formation. 2D nanoscale cloth will provide access to a new generation of smart, multifunctional materials, coatings, and surfaces.

Tn this study, we describe a method to weave a two1 dimensional cloth from polymeric strands of electroactive superatoms. Weaving nanoscale building blocks promises to endow a nanomaterial with the strength and toughness typically associated with everyday textiles but also to incorporate the emergent and tunable properties of the nanoscale subunits. It is easy to imagine that two-dimensional nanoscale cloth would provide a new generation of smart, multifunctional materials, coatings, and surfaces; ${ }^{1,2}$ yet despite this promising vision, whereas a variety of interwoven coordination polymers exist, $^{3-11}$ there are only limited and highly specific methods available to covalently form two-dimensional, woven nanomaterials. ${ }^{12}$ Here we disclose a simple route to nanoscopic $2 \mathrm{D}$ woven structures reminiscent of the weaving that produces macroscopic textiles in that an electrostatic template directs the directionality of the weaving.

The simplest weave is a box weave, in which the strands outline a square (Figure 1A). This square acts as a template that directs the strands to create four points where the strands cross over and under each other. We show here that the same principle can be applied on the nanoscale to create two-
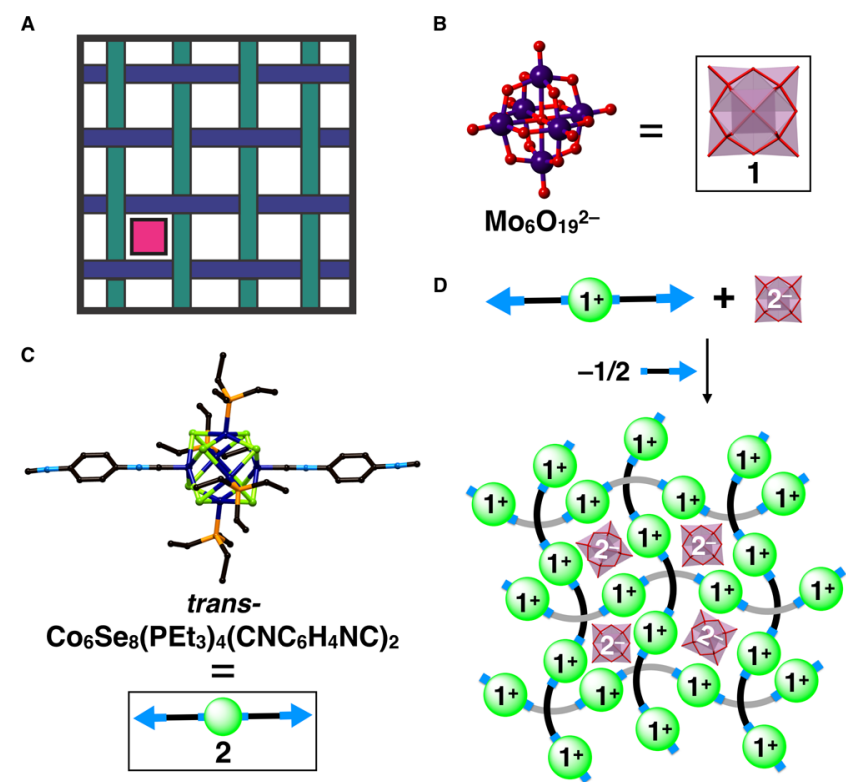

Figure 1. (A) Two-dimensional box weave. The magenta square represents a template for the box weave. (B) Lindqvist dianion $\mathrm{Mo}_{6} \mathrm{O}_{19}{ }^{2-} \mathrm{I}$ and its polyhedral representation. (C) Trans$\mathrm{Co}_{6} \mathrm{Se}_{8}\left(\mathrm{PEt}_{3}\right)_{4}\left(\mathrm{CNC}_{6} \mathrm{H}_{4} \mathrm{NC}\right)_{2}$ (2) and cartoon. (D) Two-step assembly between the $\mathrm{Mo}_{6} \mathrm{O}_{19}{ }^{2-}$ template and $\left[\mathrm{Co}_{6} \mathrm{Se}_{8}\left(\mathrm{PEt}_{3}\right)_{4}\left(\mathrm{CNC}_{6} \mathrm{H}_{4} \mathrm{NC}\right)_{2}\right]^{1+}$ to form a box weave.

dimensional molecular cloth with polymeric strands (molecular thread).

For the nanoscale weaving, we utilize an anionic template to direct and organize the position and concurrent polymerization of a superatom monomer. The counterion plays an important role in tuning and stabilizing the assembly and properties of certain cluster-based materials. ${ }^{13,14}$ Here, the anionic template and the growing strands are attracted to each other through ionic charge complementarity, and the directionality of the weave is determined by the symmetry of the template. For our initial target of the box weave, we used the Lindqvist dianion $\mathrm{Mo}_{6} \mathrm{O}_{19}{ }^{2-}$ (1, Figure 1B) because of its tetragonal symmetry. ${ }^{15-19}$ Furthermore, the shared oxygen atoms on the surface of $\mathbf{1}$ are the most basic and are known to act as hydrogen bond acceptors. ${ }^{15}$ The nanoscale threads within the weave are formed

Received: July 12, 2017

Published: August 22, 2017 
from the linking of synthetically programmed, trans-substituted $\mathrm{Co}_{6} \mathrm{Se}_{8}\left(\mathrm{PEt}_{3}\right)_{4}\left(\mathrm{CNC}_{6} \mathrm{H}_{4} \mathrm{NC}\right)_{2}$ clusters (2), which we call superatoms, ${ }^{20-23}$ into one-dimensional polymers through isonitrile-cobalt bonds (Figure 1C). ${ }^{24}$ In general, the superatoms are electroactive, and each can give up to three electrons. Recent studies have shown that these and similar metal chalcogenide clusters have low ionization potentials and can form charge-transfer complexes with electron-deficient moieties. $^{20,25,26}$ When the superatom is substituted with bisisonitriles to form $\mathbf{2}$ only the first of these oxidations is reversible (Figure S1 contains the cyclic voltammetry of 2). We have also observed that the isonitriles on the oxidized clusters became more labile and would thus encourage the substitution reaction to form the macromolecular strands. We anticipated that the cationic superatoms would associate with the anionic template and as the polymer chains grew they would express the 4-fold symmetry of the template (Figure 1D). The charge complementarity between the components creates a long-range ordered electrostatic "loom". This loom is further reinforced by the phenyl-to-phenyl distance in 2 , which corresponds to the edge length of the anionic template and encourages $\pi-\pi$ stacking in the crossing points of the woven material.

To accomplish this chemical weaving, we combined $\mathbf{1}$ and $\mathbf{2}$ in an electrocrystallization cell. Electrocrystallization is an invaluable tool for growing high quality electronic and magnetic materials in which a constant electrical current adjusts the state of oxidation of the growing components and assembles them in the solid state. ${ }^{27}$ Figure 2 displays the structure from single

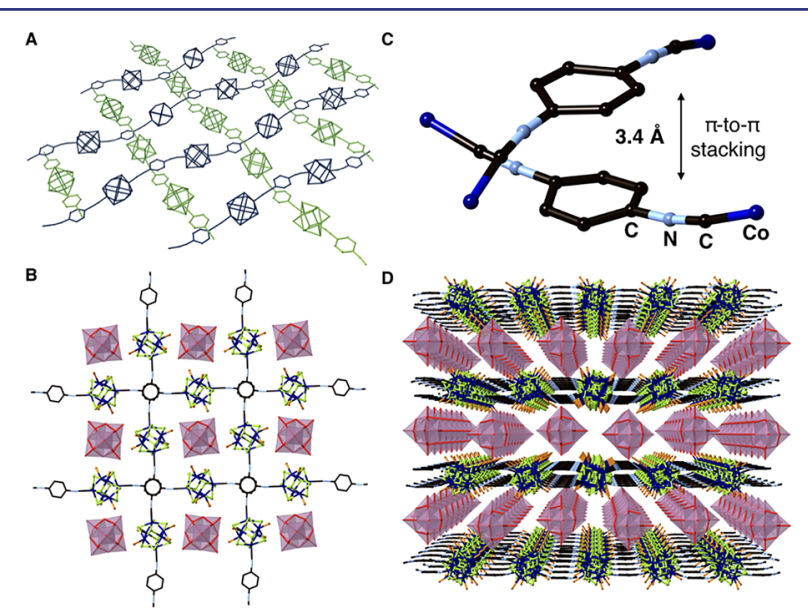

Figure 2. (A) SCXRD showing the woven structure formed from building blocks 1 and $\mathbf{2}$. The triethyl phosphine groups and hydrogen atoms have been removed to clarify the view. (B) The templation utilizes the 4-fold axis of $\mathrm{Mo}_{6} \mathrm{O}_{19}{ }^{2-}$. (C) $\pi$-to- $\pi$ interactions holding the strands in registry. (D) Side view of the crystal packing showing the cationic and anionic layers ( $a$-axis). Note that the ethyl groups from the phosphine subunits, which envelop the surface of the templating Lindquist nanooxides with directional $\mathrm{C}-\mathrm{H} \cdots \mathrm{O}$ hydrogen bonds, have been omitted in $\mathrm{B}$ and $\mathrm{D}$ to clarify the view.

crystal X-ray diffraction (SCXRD) of the assembled box weave fabric resulting from the electrocrystallization of these two components. These crystals were first grown using electrocrystallization, and subsequently annealed at $150{ }^{\circ} \mathrm{C}$ to remove any remaining, unbound isonitriles. The annealing is a crystalto-crystal transformation that preserves the tetragonal space group, $P 4 / n c c$ and long-range order of the lattice that was established by the initial electrocrystallization (Supporting Information). ${ }^{28}$
SCXRD reveals that in the annealed crystal, monodisperse polymer strands of $\mathbf{2}$ are woven into a two-dimensional material, or molecular "cloth" (Figure $2 \mathrm{~A}$ ). Each of the $\mathrm{Co}_{6} \mathrm{Se}_{8}$ clusters has a single positive charge, and the $\mathrm{Mo}_{6} \mathrm{O}_{19}$ cluster is dianionic, thus the chemical formula for the nanoscale cloth is $\left\{\left[\mathrm{Co}_{6} \mathrm{Se}_{8}\left(\mathrm{PEt}_{3}\right)_{4}{ }^{+}\right]\left(\mathrm{CNC}_{6} \mathrm{H}_{4} \mathrm{NC}\right)\right\}_{2}\left[\mathrm{Mo}_{6} \mathrm{O}_{19}{ }^{2-}\right]$. Each $\mathrm{Co}-\mathrm{C}-$ $\mathrm{N}$ angle is bent from linear by about $10^{\circ}$ to allow each strand to undulate as necessary to form the box weave. Figure $2 \mathrm{~B}$ shows how the $\mathrm{Mo}_{6} \mathrm{O}_{19}{ }^{2-}$ directs the perpendicular arrangement of strands. In addition to the electrostatic templating, the $\mathrm{Mo}_{6} \mathrm{O}_{19}{ }^{2-}$ further expresses its tetragonal symmetry through directional hydrogen bonds with the oligomeric strands. Neighboring strands cross at the aromatic rings of their linkers. The neighboring isonitriles are rotated $90^{\circ}$ with respect to each other, and they are stacked, cofacially, within their van der Waals radii of $\sim 3.4 \AA$ (Figure $2 \mathrm{C}$ ). If we substitute in the electrocrystallization experiment the Lindqvist dianion with a dianion that lacks tetragonal symmetry $\left[\left(\mathrm{W}_{6} \mathrm{Cl}_{14}\right)(\mathrm{TBA})_{2}\right]$, we do not observe the crystalline woven structure.

It is even more remarkable that the layers of the cloth pack as alternating charged layers into a stack of nanoscale fabric. The layer-by-layer packing has the anionic layer of $\mathrm{Mo}_{6} \mathrm{O}_{19}{ }^{2-}$ anions compensated by the cationic layer of nanoscale cloth (Figure 2D). Moreover, the different cationic layers are stacked in registry, thus the Lindqvist dianion not only directs the formation of two-dimensional cloth, but also of the threedimensional fabric.

The molecules-to-fabric transformation occurs in two general stages: the formation of the ionic "loom", and the subsequent interweaving of the polymeric "thread." We know this because when we omit the post-electrocrystallization annealing step, we arrest the weaving process at a partially polymerized stage and isolate the intermediate that we call the "protocloth". Figure 3 displays the SCXRD structure of the partially polymerized strands within the protocloth. The protocloth is a solid solution that has long-range order containing both woven (bridging isonitriles) and unwoven (terminal isonitriles) oligomeric fragments (details of the refinement can be found in the Supporting Information).

We find that nanoscale weaving has a further analogy to macroscopic weaving. When weaving, a "warp" strand is the stationary strand held in place by a loom through which the "weft" strand weaves. In the protocloth, there are covalently bound polydisperse, oligomeric strands, the "warp" strands, and there are segments in the crystals where the bridging reaction has not yet occurred and an extra equivalent of the bis-isonitrile linker remains, the "weft" strands (Figures 3A). The crystallographic occupancies in the crystal for the "warp" (woven) and "weft" (unwoven) strands in the protocloth are 0.64 to 0.36 , respectively, for a total stoichiometry of 1.62 bis-isonitrile per cluster. Thus, the overall formula is $\left\{\left[\mathrm{Co}_{6} \mathrm{Se}_{8}\left(\mathrm{PEt}_{3}\right)_{4}^{+}\right]\right.$$\left.\left[\left(\mathrm{CNC}_{6} \mathrm{H}_{4} \mathrm{NC}\right)_{0.36}\left(\mathrm{CNC}_{6} \mathrm{H}_{4} \mathrm{NC}\right)_{1.28}\right]\right\}_{2}\left[\mathrm{Mo}_{6} \mathrm{O}_{19}{ }^{2-}\right] \cdot \mathrm{THF}$.

The bis-isonitrile ligands are distributed with unbalanced occupancies over the four crossing points in the unit cell with distinct spatial configurations. We define the three possible crossing points as "weft-weft", "weft-warp", and "warp-warp" crossings (Figure 3B). From the crystal structure refinement, it is clear that "warp-warp" crossings cannot exist in the protocloth because this would impose an energetically unfavorable $2.7 \AA \pi$-to- $\pi$ distance between aryl rings. However, a mixture of "warp-weft", "weft-weft", and "weft-warp" crossing points are present. The "weft" strands are held in place by the electrostatic templating of the superatoms with the 
A
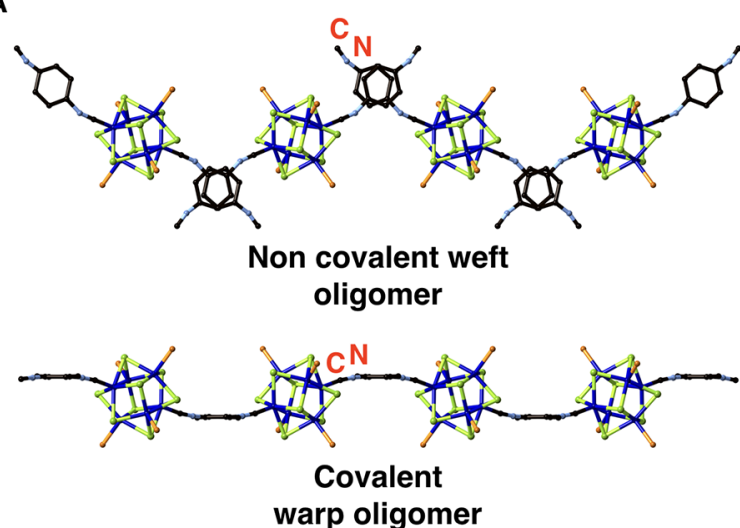

B

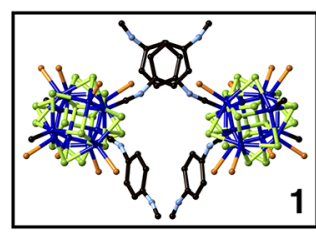

Completely unwoven (weft/weft)
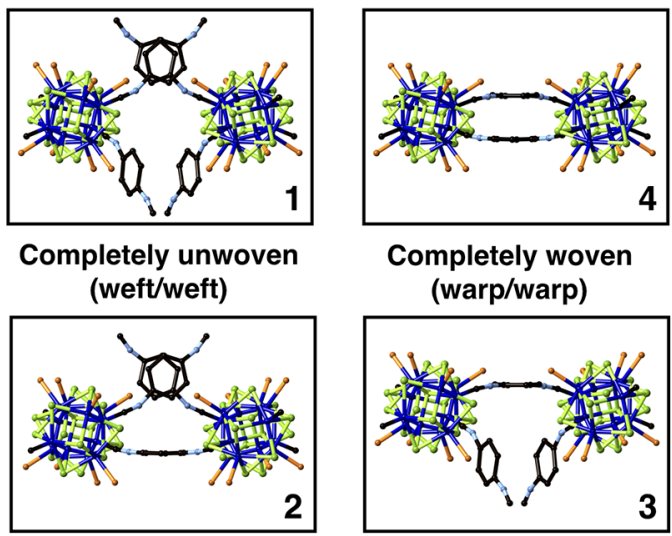

Completely woven (warp/warp)

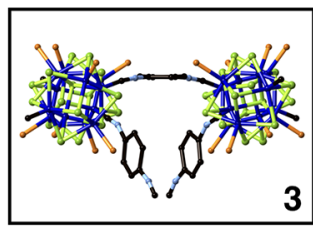

Semi-woven

(weft/warp)

Figure 3. (A) The protocloth consists of unwoven, oligomeric weft segments and woven oligomeric warp segments. (B) Different possible configurations of crossing points in the warp (woven) and weft (unwoven) strands. The warp and weft strands that make up the protocloth are polydisperse in length. The warp/warp combination does not occur in the crystal.

anions and by a loose $\pi$-stacking ( $\sim 3.5 \AA)$ between the dangling aryl-isonitriles. As such, these free isonitriles, which are in excess in the lattice, are held in a perfectly predisposed position to bridge upon heating to release the bis-isonitrile. This last transformation forms the woven cloth. ${ }^{29}$

Beyond the box weave there are other basic textile weaves such as the hexagonal weave and the octagonal weave that should now be possible (Figure 4). ${ }^{30}$ The higher order weaves differ by how the strands of thread are oriented with respect to each other. For a box weave, two strands cross each other, for a
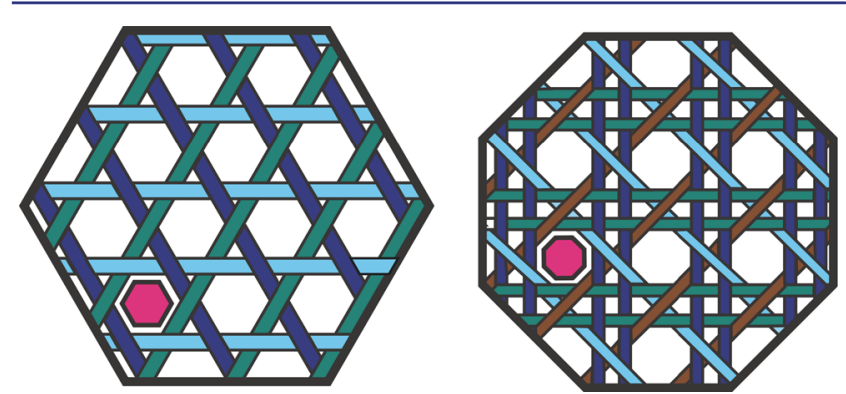

Figure 4. Higher order weaving. Hexagonal or octagonal weaving utilizes either a hexagonal or octagonal template shown in magenta. hexagonal weave three strands cross over each other, and so on for the octagonal weave. These types of weaves on the nanoscale will adjust their durability and their topology. To create these higher order nanoscale weaves, it will be necessary to utilize electrostatic templates with hexagonal symmetry and octagonal symmetry (Figure 4). ${ }^{26}$ This study reveals a method to make a new type of two-dimensional nanomaterial, a woven cloth. These materials are interesting because they could be exfoliated electrochemically to release the free-standing, twodimensional sheet. The electronic and magnetic properties of this new two-dimensional cloth will be coupled with its presumed strength and toughness that is imparted by the weave.

\section{ASSOCIATED CONTENT}

\section{(5) Supporting Information}

The Supporting Information is available free of charge on the ACS Publications website at DOI: 10.1021/jacs.7b07279.

All synthetic methods, characterization (PDF)

Data for $2\left(\mathrm{C}_{32} \mathrm{H}_{64} \mathrm{Co}_{6} \mathrm{~N}_{2} \mathrm{P}_{4} \mathrm{Se}_{8}\right), \mathrm{Mo}_{6} \mathrm{O}_{19}$ (CIF)

Data for $\mathrm{C}_{74.18} \mathrm{H}_{133.09} \mathrm{Co}_{12} \mathrm{~N}_{6.54} \mathrm{P}_{8} \mathrm{Se}_{16}, \mathrm{Mo}_{6} \mathrm{O}_{19}$, 2$\left(\mathrm{C}_{4} \mathrm{H}_{8} \mathrm{O}\right)(\mathrm{CIF})$

\section{AUTHOR INFORMATION}

\section{Corresponding Authors}

*mls2064@columbia.edu

*cn37@columbia.edu

*patrick.batail@univ-angers.fr

ORCID

Colin Nuckolls: 0000-0002-0384-5493

Notes

The authors declare no competing financial interest.

CCDC 1547794 (Proto-cloth) and CCDC 1548888 (Cloth) contain the crystallographic data for this paper. These data can be obtained free of charge from The Cambridge Crystallographic Data Centre.

\section{ACKNOWLEDGMENTS}

We thank Ryan Hastie for her help in making figures. C.N. thanks Sheldon and Dorothea Buckler for their generous support. Support for this research was provided by the Center for Precision Assembly of Superstratic and Superatomic Solids, an NSF MRSEC (award number DMR-1420634), and the Air Force Office of Scientific Research (award number FA9550-141-0381). We also thank Columbia University for support of the Columbia University Shared Materials Characterization Laboratory (SMCL) whose staff and instrumentation contributed to this work.

\section{REFERENCES}

(1) Weng, W.; Chen, P. N.; He, S. S.; Sun, X. M.; Peng, H. S. Angew. Chem., Int. Ed. 2016, 55, 6140.

(2) Wagner, S.; Bauer, S. MRS Bull. 2012, 37, 207.

(3) Luan, X. J.; Wang, Y. Y.; Li, D. S.; Liu, P.; Hu, H. M.; Shi, Q. Z.; Peng, S. M. Angew. Chem., Int. Ed. 2005, 44, 3864.

(4) Han, L.; Zhou, Y. Inorg. Chem. Commun. 2008, 11, 385.

(5) Baburin, I. A.; Blatov, V. A.; Carlucci, L.; Ciani, G.; Proserpio, D. M. J. Solid State Chem. 2005, 178, 2452.

(6) Blatov, V. A.; Carlucci, L.; Ciani, G.; Proserpio, D. M. CrystEngComm 2004, 6, 377.

(7) Carlucci, L.; Ciani, G.; Proserpio, D. M. Coord. Chem. Rev. 2003, 246, 247. 
(8) Hyde, S. T.; Chen, B. L.; O’Keeffe, M. CrystEngComm 2016, 18, 7607.

(9) Alexandrov, E. V.; Blatov, V. A.; Proserpio, D. M. Acta

Crystallogr., Sect. A: Found. Crystallogr. 2012, 68, 484.

(10) Wadhwa, N. R.; Hughes, N. C.; Hachem, J. A.; Mezei, G. RSC Adv. 2016, 6, 11430 .

(11) Liu, Y. Z.; Ma, Y. H.; Zhao, Y. B.; Sun, X. X.; Gandara, F.; Furukawa, H.; Liu, Z.; Zhu, H. Y.; Zhu, C. H.; Suenaga, K.; Oleynikov, P.; Alshammari, A. S.; Zhang, X.; Terasaki, O.; Yaghi, O. M. Science 2016, 351, 365.

(12) Wang, Z. B.; Blaszczyk, A.; Fuhr, O.; Heissler, S.; Woll, C.; Mayor, M. Nat. Commun. 2017, 8, 14442.

(13) Qian, M. C.; Reber, A. C.; Ugrinov, A.; Chaki, N. K.; Mandal, S.; Saavedra, H. M.; Khanna, S. N.; Sen, A.; Weiss, P. S. ACS Nano 2010, 4, 235 .

(14) Mandal, S.; Reber, A. C.; Qian, M. C.; Weiss, P. S.; Khanna, S. N.; Sen, A. Acc. Chem. Res. 2013, 46, 2385.

(15) Dolbecq, A.; Guirauden, A.; Fourmigue, M.; Boubekeur, K.; Batail, P.; Rohmer, M. M.; Benard, W.; Coulon, C.; Salle, M.; Blanchard, P. J. Chem. Soc., Dalton Trans. 1999, 1241.

(16) Coronado, E.; Gomez-Garcia, C. J. Chem. Rev. 1998, 98, 273.

(17) Che, M.; Fournier, M.; Launay, J. P. J. Chem. Phys. 1979, 71, 1954.

(18) Davidson, A.; Boubekeur, K.; Penicaud, A.; Auban, P.; Lenoir, C.; Batail, P.; Herve, G. J. Chem. Soc., Chem. Commun. 1989, 1373.

(19) Fourmigue, M.; Batail, P. Chem. Rev. 2004, 104, 5379.

(20) Roy, X.; Lee, C. H.; Crowther, A. C.; Schenck, C. L.; Besara, T.; Lalancette, R. A.; Siegrist, T.; Stephens, P. W.; Brus, L. E.; Kim, P.; Steigerwald, M. L.; Nuckolls, C. Science 2013, 341, 157.

(21) Khanna, S. N.; Jena, P. Phys. Rev. B: Condens. Matter Mater. Phys. 1995, 51, 13705.

(22) Luo, Z. X.; Castleman, A. W. Acc. Chem. Res. 2014, 47, 2931.

(23) Walter, M.; Akola, J.; Lopez-Acevedo, O.; Jadzinsky, P. D.; Calero, G.; Ackerson, C. J.; Whetten, R. L.; Gronbeck, H.; Hakkinen, H. Proc. Natl. Acad. Sci. U. S. A. 2008, 105, 9157.

(24) Champsaur, A. M.; Velian, A.; Paley, D. W.; Choi, B.; Roy, X.; Steigerwald, M. L.; Nuckolls, C. Nano Lett. 2016, 16, 5273.

(25) Chauhan, V.; Reber, A. C.; Khanna, S. N. J. Am. Chem. Soc. 2017, 139, 1871.

(26) Turkiewicz, A.; Paley, D. W.; Besara, T.; Elbaz, G.; Pinkard, A.; Siegrist, T.; Roy, X. J. Am. Chem. Soc. 2014, 136, 15873.

(27) Batail, P.; Boubekeur, K.; Fourmigue, M.; Gabriel, J. C. P. Chem. Mater. 1998, 10, 3005.

(28) Details for the electrochemistry and SCXRD can be found in the Supporting Information.

(29) We also note that there is tetrahydrofuran located in the equatorial plane of Lindqvist anions in the crystal which, when heated, is expelled along with unbound bis-isonitriles to complete the weave.

(30) Boubekeur, K.; Riccardi, R.; Batail, P.; Canadell, E. C. R. Acad. Sci., Ser. IIc: Chim. 1998, 1, 627. 